\title{
ACOLHIMENTO NO PROGRAMA SAÚDE DA FAMÍLIA: UM CAMINHO PARA HUMANIZAÇÃO DA ATENÇÃO À SAÚDE
}

[The welcoming in the family health program: a way to humanize health]

Maria de Fátima de Araújo Silveira*

Lidiany Galdino Felix**

Daísy Vieira de Araújo**

lane Carvalho da Silva**

RESUMO: Atualmente no contexto do Programa Saúde da Família (PSF), o Acolhimento representa um importante instrumento para a humanização da atenção à saúde. Assim, este trabalho tem por objetivos identificar a concepção que os profissionais do PSF têm de acolhimento, descrever como estes profissionais praticam o acolhimento, identificando as condições favoráveis e desfavoráveis para a consolidação de uma cultura da humanização no PSF. O estudo tem abordagem qualitativa, do tipo etnográfica, e os dados foram colhidos no contexto de uma oficina de sensibilização, criatividade e expressividade. Os resultados demonstram que a cultura que os profissionais têm sobre o acolhimento está relacionada aos seguintes conceitos: "receber bem", "ouvir o usuário", "estar atento", "compreender" e "solidarizar-se". Conclui-se que, apesar das limitações institucionais, profissionais e sociais relatadas, estes profissionais vivenciam diariamente a prática do acolhimento da forma mais humana de sua concepção, extrapolando, para isso, até mesmo sua formação profissional, que, geralmente, habilita-os para ações curativas.

PALAVRAS-CHAVE: Acolhimento; Humanização; Programa Saúde da Família.

*Professora Titular do Departamento de Enfermagem da Universidade Estadual da Paraíba/UEPB. Doutora em Enfermagem pela Escola de Enfermagem da USP/São Paulo.

**Acadêmicas do Curso de Graduação em Enfermagem - Universidade

Estadual da Paraíba/UEPB e bolsistas do Programa de Iniciação

Científica/CNPQ.

\section{INTRODUÇÃO}

O Programa Saúde da Família (PSF), ao se constituir em uma estratégia de mudança e reordenamento do modelo assistencial no Brasil, propõe-se a alavancar o Sistema Único de Saúde (SUS) que, apesar dos avanços jurídico-políticos, não foi capaz de reverter o quadro sócio-sanitário nacional, regional ou local, permanecendo como hegemônico o modelo assistencial individual, curativo, cujo centro é o hospital.

Um pilar essencial na construção do novo modelo de atenção básica é a humanização que a proposta do PSF tem por objetivo contemplar, por meio do estabelecimento de vínculo entre profissionais/usuários/famílias, através da responsabilização da equipe na resolução dos problemas de saúde da comunidade.

Nesse âmbito, a estratégia do acolhimento é uma ação implantada em alguns municípios, visando o alcance do objetivo de oferecer serviços de saúde a partir de critérios técnicos, éticos e humanísticos. Acolher, no contexto dos serviços de saúde, é "receber bem, ouvir a demanda, buscar formas de compreendê-la e solidarizar-se com ela. Deve ser realizada por toda equipe de saúde, em toda relação profissional de saúde-pessoa em cuidado" (PAIDÉIA, 2001).

Experiências nessa direção vêm sendo desenvolvidas objetivando organizar a oferta de serviços de saúde, a partir da escuta das necessidades e demandas da clientela, avaliando e tomando como critérios o risco de cada situação que deverá pautar a conduta a ser tomada (LEITE 
et al., 1999; FRANCO et al., 1999; PAIDÉIA, 2002).

Contudo, uma incursão pelos referidos trabalhos e outros textos permite compreender que o acolhimento tem se efetivado como uma atividade, com hora e objetivo específico a ser alcançado - garantir o acesso dos usuários - a ser realizado por determinados profissionais, a depender do serviço, em local específico para esse fim, o que exprime a noção reduzida do acolhimento como forma de organizar a oferta dos serviços (LEITE et al., 1999; PAIDÉIA, 2001), havendo casos em que até um protocolo de acolhimento foi instituído, visando a esse fim (PAIDÉIA, 2002). E, como instrumento de modificação no critério de marcação de consultas, o acolhimento tem se traduzido em triagem.

Tais constatações levam à reflexão de que o acolhimento precisa ser considerado um instrumento de trabalho que incorpore as relações humanas, apropriado por todos os profissionais em saúde, em todos os setores, em cada seqüência de atos e modos que compõem o processo de trabalho, não se limitando ao ato de receber (FRACOLLI \& BERTOLOZZI, 2003).

Em Campina Grande, o PSF foi implantado em 1994, inicialmente com quatro equipes, e hoje conta com quarenta e nove equipes inseridas em trinta e sete unidades de saúde. Embora não disponha de um serviço de acolhimento formalmente estruturado, mas, considerando-se que o acolhimento envolve todas as ações de saúde, e tomando-se como premissa que acolher é, sobretudo, uma escuta sensível, foram estabelecidos os seguintes objetivos: identificar a concepção que os profissionais do PSF têm de acolhimento; descrever como os profissionais praticam o acolhimento, identificando as condições favoráveis e desfavoráveis à consolidação de uma cultura da humanização no PSF.

\section{METODOLOGIA}

O estudo foi realizado por meio de uma abordagem qualitativa. A pesquisa qualitativa, segundo Polit \& Hungler (1995), baseia-se na premissa de que os conhecimentos sobre os indivíduos só são possíveis com a descrição da experiência humana tal como ela é vivida e tal como ela é definida por seus próprios atores. Como decorrência, tem a finalidade de compreender as experiências no seu todo, na perspectiva dos participantes.

Como método, optou-se pelo etnográfico, fundamentado no conceito de cultura, uma vez que é adequado para compreender o modo como o grupo composto pelos profissionais da equipe de saúde da família tem vivido o acolhimento.

A etnografia é uma metodologia propícia para descobrir essa maneira de viver e as experiências das pessoas, pois, além da obtenção de dados, possibilita ao pesquisador o aprendizado com o grupo no qual se insere para realizar a pesquisa de campo. Dessa forma, a etnografia se constitui em processo e produto de investigação, envolvendo "uma atitude de aprender com, ao invés de estudar as pessoas" (GUALDA et al., 1995, p. 303).

A amostra foi constituída por acessibilidade, sendo composta por profissionais integrantes de duas equipes do Programa Saúde da Família da cidade de Campina Grande, na Paraíba, que se dispuseram, após serem convidados, a participar da pesquisa, totalizando 11 profissionais, sendo (2) enfermeiras, (2) auxiliares de enfermagem e (7) agentes comunitários de saúde. Os profissionais de odontologia e serviço social não foram incluídos na pesquisa porque, na época da realização da mesma, estes profissionais não faziam parte das equipes estudadas. Outro ponto importante a destacar é que, apesar do convite, os médicos que atuam nestas duas equipes se recusaram a participar da pesquisa.

Por se coadunar com o método etnográfico, que possibilita um aprendizado coletivo, os dados foram colhidos no contexto de uma oficina de sensibilização, criatividade e expressividade, a partir da experiência de Silveira \& Garcia (1998), Silveira (2001) e Silveira et al. (2002).

A oficina foi realizada em Janeiro de 2003 e foi constituída pelas fases de: integração, apresentação, relaxamento, desenvolvimento do tema, incluindo a reflexão e a discussão, síntese e descontração. O processo, após autorização das participantes, foi fotografado e, para obtenção dos dados e discursos, as falas foram gravadas em fitas cassetes que, posteriormente, foram transcritas na íntegra.

Em busca de responder às questões levantadas e 
alcançar os objetivos propostos, os discursos foram organizados em categorias, procurando-se identificar os temas mais relevantes para interpretação, proposta por Ricouer (1976), e os dados foram apresentados na forma de narrativa. Para operacionalização da pesquisa, as participantes assinaram o Termo de Consentimento Livre e Esclarecido, de acordo com a Resolução 196/96 do Conselho Nacional de Saúde (BRASIL, 1996), sendo Ihes garantido, a voluntariedade e o direito à desistência em participar do estudo, sem sofrer nenhum dano ou prejuízo profissional, além do total anonimato e sigilo das informações confidenciadas.

\section{RESULTADOS E DISCUSSÃO}

\section{Concepção que os profissionais do PSF têm de acolhimento}

A análise dos discursos das profissionais participantes desta pesquisa permite apreender que, apesar do PSF de Campina Grande não possuir um serviço de acolhimento formalmente estruturado, os profissionais realizam o acolhimento e têm sobre este, vários conceitos que se coadunam com a literatura revisada. Foi consenso entre os profissionais presentes na oficina que acolher implica receber bem o usuário ou a clientela, como expresso no discurso: “... Receber com alegria, ter respeito por eles e tratálos como gente... (Enfermeira 1)"

Essa concepção dos profissionais encontra respaldo no conceito de Paidéia (2001), que ainda afirma que, para acolher, é preciso desenvolver maneiras de receber os distintos modos com que a população busca ajuda nos serviços de saúde, respeitando o momento existencial de cada um, sem abrir mão de colocar limites necessários.

Outra concepção que emergiu foi a de que acolher não se limita apenas à recepção da clientela, mas envolve a escuta das necessidades do usuário: “... Ele já vem com aquela dificuldade, querendo um socorro seja lá qual... então, assim, se a gente não dá nem importância, não quer nem ouvir o usuário, eu acho assim, isso já é uma forma dele sair magoado (Auxiliar de enfermagem 1)".

O que percebemos com a descrição do discurso acima é que o acolhimento pode significar não só a resolução completa dos problemas que o usuário apresenta, mas a atenção dispensada, através da escuta, à valorização das queixas e à identificação das necessidades, transformadas em objeto de ação de saúde (TEIXEIRA et al., 2000).

Ainda com relação à cultura do acolhimento que está sendo construída pelos profissionais do PSF em Campina Grande, encontra-se o "estar atento" como uma concepção de acolhimento: "Um olhar bem acolhedor a essa pessoa... vai observar os problemas, o motivo pelo qual ela veio ali... observar a aflição dela, de que modo ela quer ser atendida. Estar atento às palavras que as pessoas expressam nesse momento que você recebe, tanto a que você passa, como a de quem tá chegando e tá dizendo. (Enfermeira 2)"

Leite et al. (1999) afirmam que, para humanizar a relação serviço x profissional de saúde x usuário, não basta considerar a questão da responsabilidade, do respeito, pressupostos para a realização da assistência. É necessário ultrapassar essa visão afetuosa da atenção e discutir o modo como os trabalhadores se relacionam com seu principal objeto de trabalho a vida e o sofrimento de indivíduos e da coletividade.

Nesse sentido, a perspectiva do usuário fornece informação essencial para completar e equilibrar a qualidade dos serviços (TRAD et al., 2002). Este estar atento, segundo os profissionais, implica, também, buscar novas formas de compreender e solidarizar-se com a demanda: “... é fazer com que ela não se sinta sozinha, né?... fazer uma amizade, dar uma força a ela, dar opinião a ela, uma luz de alguma coisa (ACS 7)."

Assim, o serviço de saúde assume sua função precípua, a de acolher e dar uma resposta positiva, capaz de resolver os problemas de saúde da população. E, como etapa do conjunto do processo de trabalho que o serviço desencadeia na sua relação com o usuário, o acolhimento pode revelar uma dinâmica instituidora que se abre a novas linhas de possibilidades, no desenho do modo de se trabalhar em saúde, permitindo a introdução de modificações no cotidiano do serviço em torno de um processo usuário-centrado, mais comprometido com a defesa da vida individual e coletiva (FRANCO et al., 1999). 
Como os profissionais praticam o acolhimento

$\mathrm{Na}$ descrição da prática do acolhimento, verifica-se que existe uma preocupação, e até mesmo uma responsabilização dos profissionais do PSF, na busca de soluções para os problemas da população, o que corrobora os argumentos de Vasconcelos (1999), quando o mesmo afirma que muitos problemas apresentados pelas famílias assistidas em unidades básicas de saúde são profundos demais para serem curados, mas não para serem cuidados. "Eu acho que o nosso papel é resgatar também nas pessoas o otimismo... se a gente conseguir passar pra nossa comunidade que eles são capazes de aprender a viver melhor, eu acho que já é grande coisa, a gente já fez o máximo! (ACS 3)"

O enunciado acima mostra que as ações educativas voltadas à população usuária, diferentemente dos resultados obtidos por Leite et al. (1999), dão uma perspectiva de mudança de conduta e contribuem para que os indivíduos conquistem sua autonomia e qualifiquem seu modo de "levar a vida".

Olhando esses momentos pela ótica tanto dos profissionais de enfermagem quanto pela de uma ACS, são-nos reveladas questões-chave sobre os processos de produção em saúde, nos quais o acolhimento adquire uma expressão significativa, que, para Franco et al. (1999), operase através de processos tecnológicos (trabalho vivo em ato) que visam à produção de relações de escutas e responsabilizações, as quais se articulam com a constituição dos vínculos e dos compromissos em projetos de intervenção. Estes, por sua vez, objetivam atuar sobre necessidades em busca da produção de algo que possa representar a conquista de controle ou amenização do sofrimento (enquanto doença) e/ou à produção da saúde. "A gente já teve uma criança com nove meses que pesava três quilos e meio, e a gente só conseguiu tirar essa criança da desnutrição com a ajuda da ACS que tava lá todo dia alimentando a criança, porque a mãe tava nem aí pra estória. Como a desnutrição é uma constante... a gente fez um show beneficente... graças a Deus, o show deu certo. A gente arrecadou umas noventa e poucas latas de leite e vem distribuindo leite com as crianças mais carentes... (Auxiliar de enfermagem 2)"
Tais mudanças vêm se alinhando ao desenho de um novo perfil de profissionais, que se encontram mais sensíveis para perceber as reais necessidades da população, produzindo uma atenção capaz de gerar satisfação social e excelência técnica, de forma resolutiva, para as pessoas e a sociedade (PIANCASTELLI et al., 2000). "A gente procura sempre mostrar pra elas que o trabalho do PSF é diferente! Não é aquela coisa tradicional, que a pessoa chega e o médico não olha nem pra cara e já vai passando remédio e já vai embora e tchau... eles são tão acostumados a não serem bem tratados, que, no começo, eles acham até chato, aí depois vai se acostumando. (Enfermeira 1)"

Nesta perspectiva, o PSF foge da concepção usual dos programas tradicionais concebidos no Ministério da Saúde, por não se tratar de intervenção pontual no tempo e no espaço e tampouco de forma vertical ou paralela às atividades rotineiras dos serviços de saúde. Ao contrário, objetiva a integração e a organização das atividades em um território definido, com o propósito de enfrentar e resolver os problemas identificados, com vistas a mudanças radicais no sistema, de forma articulada e perene (SOUSA, 2000a).

Segundo Santos et al. (2000), é no cotidiano, no concreto do espaço da família, que os profissionais do sistema, em interação com esta, buscam a construção da saúde, priorizando a proteção, a promoção do autocuidado, a troca solidária, procurando, dessa maneira, sair do modelo biomédico dependente, centrado na doença. Vê-se, assim, que a filosofia que o perpassa é mais do que uma simples extensão de serviços, pois enseja uma prática que oportunize crítica, mudanças, construção de saber. Os discursos a seguir caracterizam bem o modo como o acolhimento está sendo vivenciado no cotidiano destes profissionais: "Quando eu chego numa casa, por mais humilde que seja, pode ser a mais pobre, a mais suja, eu entro, sento, procuro conversar, brincar com a criança, fazer alguma coisa pra mostrar que a gente tá ali pra ajudá-los. Então, essa questão da acolhida, do respeito por eles é importantíssima (Enfermeira 1)" "A minha acolhida com a família, é fazer com que ela não se sinta sozinha, né? se tiver com algum problema, 
tentar resolver de alguma forma, dar uma força a ela, pra ela saber que não tem só uma agente de saúde e sim uma amiga, né? (ACS 7)"

Esses exemplos cotidianos nos remetem à visão de que o "acolher" não significa a resolução completa dos problemas referidos pelo usuário, mas a atenção dispensada na relação, envolvendo a escuta, a valorização de suas queixas, a identificação das necessidades, sejam estas do âmbito individual ou coletivo, e a sua transformação em objeto das ações da saúde (FRACOLLI \& BERTOLOZZI, 2003).

Contudo, é importante destacar que, apesar da concepção de acolhimento entre os diferentes profissionais ter sido consoante às apresentadas pela literatura estudada, as enfermeiras, mesmo reconhecendo a importância que o acolhimento representa para a conquista do usuário, ainda associam sua prática à sala-de-espera. Demonstrando implicitamente que, para elas, o acolhimento deve ser praticado como mais uma atividade, uma sala dentro da unidade, restringindo-se apenas ao momento de repasse de informações para o usuário.

\section{Condições favoráveis e desfavoráveis à vivência do acolhimento}

Ao analisar as facilidades para a vivência do acolhimento, apreende-se que, no contexto do que foi debatido durante a oficina, todas as profissionais apontaram a integração e o relacionamento satisfatório entre a equipe, bem como a receptividade da comunidade, como facilitadores para a realização de um acolhimento humanizado. "Eu acho que a acolhida deve partir da equipe como um todo. (Enfermeira 2)"

Estas manifestações permitem inferir sobre a concepção de que o trabalho em equipe sustenta as práticas destes profissionais, conforme os dados apresentados por Leite et al., (1999). Nesta nova composição, a complementaridade entre o trabalho dos diferentes profissionais apresenta-se como elemento que leva à superação da prática individual, uma cultura ainda corrente na formação e prática dos profissionais de saúde.

Os discursos referentes às condições desfavoráveis para a realização do acolhimento foram analisados e reunidos em três categorias: relacionados ao processo e organização do trabalho; aos profissionais e aqueles relacionados às condições sociais da comunidade.

Analisando as dificuldades relativas ao processo e organização do trabalho, verifica-se que somente as enfermeiras as descrevem, sendo que, para estas, as condições desfavoráveis estão relacionadas à inadequada área física, à demanda excessiva e à falta de médico na unidade. "O nosso tempo é muito corrido! Tem dia que eu tenho dezesseis crianças marcadas pra atender, então, se eu não começar a atender logo, elas vão achar ruim, porque vão ficar a manhã todinha esperando. (Enfermeira 1)".

Essas queixas com relação ao aspecto organizacional remetem àquilo que ainda está insuficiente, precário ou inexistente. Fica patente que, para haver uma modificação expressiva do modelo assistencial e a humanização do atendimento, é preciso redirecionar a organização e distribuição das ações e serviços de modo a responder satisfatoriamente às demandas, bem como às necessidades de saúde e, para isso, é necessário associar práticas de atendimento à demanda espontânea e de vigilância à saúde.

Com relação ao excesso de demanda que eleva o tempo de espera por consultas, Trad et al. (2002) afirmam, em seu estudo etnográfico sobre a satisfação do usuário do PSF da Bahia, que o fato de o PSF atender a uma clientela adstrita a uma área determinada é visto pelas equipes como extremamente positivo, pois, além de facilitar a criação de vínculo com a comunidade atendida, permite maior conhecimento da realidade com a qual se trabalha. Contudo, a dificuldade de refrear a demanda espontânea nas áreas atendidas configura-se como um nó crítico na realização das atividades da equipe.

Franco \& Merhy (2003) consideram que a forma como os mentores do PSF podem organizar e estruturar a demanda de serviços da UBS, a partir exclusivamente de usuários que devem ser referenciados pelas equipes do PSF, elimina a possibilidade de atendimento à demanda espontânea, o que se constitui em uma doce ilusão, pois a população continua recorrendo aos serviços de saúde em situações de sofrimentos e angústias, e, não havendo um esquema para atender-Ihe e dar uma resposta satisfatória aos seus problemas agudos de saúde, ela vai desembocar nas Unidades 
de Pronto Atendimento e Prontos-Socorros, como usualmente acontece.

Ainda com relação às condições desfavoráveis para a consolidação de uma cultura de humanização no PSF, é importante destacar que, em todos os discursos das ACS participantes da pesquisa, verifica-se que o agente de saúde enfrenta sérias dificuldades profissionais relacionadas às suas condições salariais, como expresso no seguinte discurso: "Implantou-se o PSF em Campina Grande. Eu acho que o enfermeiro ganha enquanto PSF, auxiliar de enfermagem ganha enquanto PSF, o médico ganha enquanto médico de PSF, até reivindicando melhores salários. Mas o agente de saúde, ele não foi reconhecido enquanto agente de saúde do PSF. Somos PSF, ganhamos enquanto PACS, mas nos cobram enquanto PSF! (ACS 3)"

Souza (2000b) nos lembra que a grande especificidade do ACS, que o diferencia da equipe, é que ele vive e intervém no processo saúdedoença da comunidade num nível de interação próprio de quem participa de um mesmo universo simbólico, de uma mesma cultura. Assim, embora todos estejam preocupados com questões de promoção à saúde, o ACS é o elemento central para fomentar movimentos sociais por melhores condições de vida (moradia, transporte, educação, lazer, acesso a serviços de saúde), pelo sentimento único de pertencer àquela comunidade.

Outro aspecto negativo apontado pelas participantes, que dificulta a realização do acolhimento, são as dificuldades relacionadas às condições sociais da comunidade em que atuam. "A gente tem um índice de analfabetismo lá imenso, as pessoas vivem assim, totalmente perdidas... $90 \%$ das casas não têm banheiro, $100 \%$ do esgoto é a céu aberto, a maioria não tem água saneada em casa. Então, até que a gente consiga trabalhar isso na acolhida, é muito difícil. (Enfermeira 1)".

As condições de vida dessas famílias são as mesmas de muitas espalhadas pelo Brasil, marcadas principalmente por dificuldades financeiras, falta de emprego e uma infra-estrutura comunitária mínima, onde predominam carências patentes no que tange à segurança pública, escolas, creches e outras relacionadas à qualidade de vida. São famílias que vivem em moradias precárias, construídas de forma irregular e de dimensão bastante reduzida, que apresentam uma tendência a apresentar doenças crônicas ligadas ao estresse, resultante de uma rotina cotidiana monótona e fastidiosa, na qual predomina a falta de lazer e distração, como demonstrado nos estudos de Dytz (2000).

Quando se considera o ponto de vista das profissionais, percebe-se que os problemas de saúde da população, muitas vezes, são resultado de um processo complexo e dinâmico que se produz no interior da sociedade. Para Piancastelli et al. (2000), a saúde é resultante de um conjunto de fatores sociais, econômicos, comportamentais e também biológicos, sendo o sintoma ou sinal físico, compreendido por Fracolli \& Bertolozzi (2003), como reflexo das condições de vida e de trabalho dessa pessoa, como falta de dinheiro para pagar uma dívida vencida, a habitação não acabada ou a alimentação mal conservada.

Por tudo isso, pode-se dizer que a precariedade das condições sociais a que estas pessoas estão submetidas diariamente levam-nas, muitas vezes, a uma resistência às estratégias de acolhimento desenvolvidas pelos profissionais que atuam nas equipes do PSF. Assim, quando se considera a perspectiva das entrevistadas, verificase que, para acolher bem, é preciso também que haja uma boa acolhida por parte da comunidade.

\section{CONCLUSÃO}

Os dados coletados neste estudo permitem apreender que o acolhimento no PSF de Campina Grande ainda é uma cultura em construção, uma vez que o Programa é relativamente novo e pressupõe toda a reorientação do modelo assistencial vigente.

Neste sentido, a cultura que os profissionais têm sobre o acolhimento está relacionada aos seguintes conceitos: "receber bem", "ouvir o usuário", "estar atento", "compreender e solidarizarse". Conceitos estes que corroboram a concepção de acolher no contexto dos serviços de saúde e tão ressaltados pela literatura estudada.

Finalmente, pode-se afirmar que, apesar das limitações institucionais, profissionais e sociais relatadas pelos participantes desta pesquisa, e ainda que alguns profissionais idealizem sua prática à sala-de-espera, o que transparece de 
forma enfática em todo este trabalho de investigação sobre o acolhimento, é que estes profissionais vivenciam diariamente esta prática da forma mais humana de sua concepção, pois, no contexto social em que trabalham, além de acolher os usuários, são obrigados, também, a acolher a fome, a miséria e a desesperança que acompanham essas pessoas, transformando o acolhimento em ação concreta, extrapolando para isso até mesmo sua formação profissional, que, geralmente, habilita-os para ações curativas.

ABSTRACT: Presentelly, in the context of Family Health Program (abbreviated PSF in Portuguese), it was observed that Welcoming is an important instrument for the humanization of health. Thus, this study objectifies to identify what the PSF really is and to explain how these professionals carry out the welcoming, identifying the favorable and unfavorable conditions that might help in the consolidation of humanization culture in the PSF. This study used the qualitative approach, ethnografhic type; data were obteined in a workshop of sensitivity, creativity and expression. The results demonstrated that the culture that the professionals have acquired so far on welcoming is related to the following conception: "receive well", "listen to the users", "to be observant", "to understand", "to sympathize". It was conclude that, in spite of the reported institutional, professional and social limitations, these professionals experience daily welcoming practice in the most humanized way, even if this means that they have to go beyond their professional background, which generally educated them for healing actions.

KEY WORDS: Welcoming; Humanization; Family Health Program.

\section{REFERÊNCIAS}

BRASIL. Resolução no 196, de 10 de outubro de 1996. Dispõe sobre as diretrizes e normas regulamentadoras de pesquisa envolvendo seres humanos. Diário Oficial da União, Brasília, DF, 16 out. 1996.

DYTZ, J.L.G. O modo de vida da mãe e a saúde infantil. Rev. Bras. de Enferm., Brasília, v. 53, n.esp.,1 p.65-166, 2000.
FRACOLLI, L.A.; BERTOLOZZI, M.R. A Abordagem do processo saúde-doença das famílias e do coletivo: manual de enfermagem, Janeiro 2003 <http://www.ids-saude.org.br/ enfermagem>

FRANCO, T.B. et al. Acolhimento e os processos de trabalho em saúde: o caso de Betim, Minas Gerais, Brasil. Cadernos de Saúde Pública, Rio de Janeiro, v.15, n. 2, p.345-353, 1999.

FRANCO, T.B.; MERHY, E. PSF. Contradições e novos desafios. Conferência Nacional de Saúde On-line, Abril 2003 <http://www.datasus.gov.br/ cns.htm>

GUALDA, D.M.R et al. Abordagens qualitativas: sua contribuição para a enfermagem. Revista da Escola de Enfermagem da USP, v. 29, n. 3, p.297309, 1995.

LEITE, J.C.A. et al. Acolhimento: perspectiva de reorganização da assistência de enfermagem. Rev. Bras. de Enferm., Brasília, v. 52, n. 2, p.161-168, 1999.

PAIDÉIA 2001. Protocolo de Acolhimento da Secretaria Municipal de Saúde de Campinas. Maio 2002 <http://www.campinas.sp.gov.br>.

PAIDÉIA 2002. Projeto Paidéia de saúde da família - Campinas, Maio 2002 <http:// www.campinas.sp.gov.br>

PIANCASTELLI, C.H. et al. Saúde da família e desenvolvimento de recursos humanos. Divulgação em Saúde para Debate, n. 21, p.4448, 2000.

POLIT, D.F.; HUNGLER, B.P. Fundamentos de pesquisa em Enfermagem. Porto Alegre: Artes Médicas, 1995.

RICOUER, P. Teoria da interpretação - o discurso e o excesso de significação. Lisboa: Edições 70, 1976.

SANTOS, B. R. L. et al. Formando o enfermeiro para o cuidado à saúde da família: um olhar sobre 
ensino de graduação. Rev. Bras. de Enferm., Brasília, v. 53, n.esp., p.49-59, 2000.

SILVEIRA, M. F. A.; GARCIA, A. M.G.S. Um caminho de liberdade: a experiência da disciplina Semiologia e Semiotécnica. Rev. Bras. de Enferm., Brasília, v. 51, n. 2, p. 231-244, 1998.

SILVEIRA, M.F.A. A sagração das flores: um ritual para encantar o corpo da mulher no cuidado. São Paulo, 2001. Tese (Doutorado) - Escola de Enfermagem, Universidade de São Paulo.

SILVEIRA, M.F.A. et al. The dance of discoveries. Internacional Journal of Qualitative Methods, v.1, n. 10, article 7. Março $2002<$ http:// www.ualberta.ca/ ijqm/>.

SOUSA, M.F. A enfermagem reconstruindo sua prática: mais que uma conquista no PSF. Rev. Bras. de Enferm., Brasília, v. 53, n.esp., p.25-30, 2000a.

SOUZA, H.M. Programa saúde da família: entrevista. Rev. Bras. de Enferm., Brasília, v. 53, n.esp., p.7-16, 2000b.

TEIXEIRA, R.A. et al. O trabalho de enfermagem em atenção primária à saúde - assistência à saúde da família. Rev. Bras. de Enferm., Brasília, v. 53, n. 2, p.193-206, 2000.

TRAD, L.A. et al. Estudo etnográfico da satisfação do usuário do Programa de Saúde da Família (PSF) na Bahia. Ciência \& Saúde Coletiva, Rio de Janeiro, v. 7, n. 3, p. 581-589, 2002.

VASCONCELOS, E.M. Educação popular e a atenção à saúde da família. São Paulo: Hucitec, 1999. 